\title{
Schema Theory And L2 Reading Comprehension: Implications For Teaching
}

\author{
Ahmad Al-Issa, (Email: aissa@aus.edu), American University of Sharjah, United Arab Emirates
}

\begin{abstract}
Reading is a multileveled and interactive process in which readers construct a meaningful representation of text using their schemata. While it has been known for some time that both content and formal schemata are necessary for a complete understanding of written texts in a reader's first language (L1), and has been suspected to be true in a reader's second language (L2), it is still an area that has been generally ignored by both researchers and classroom teachers. The purpose of this paper is threefold. The first is to give a brief overview of some of the literature that deals with schema theory as part of a reader centered psycholinguistic processing model for both native and non-native readers. The second goal is to show how familiarity with the subject matter (i.e., content schema) as one aspect of schema theory, affects L2 reading comprehension. The third goal is to discuss the implications of schema theory in L2 classrooms.
\end{abstract}

\section{SCHEMA THEORY: AN INTRODUCTION}

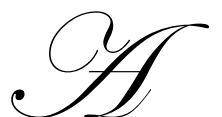

n important aspect of cognitive science, schema theory is a theory of how knowledge is acquired, processed, and retrieved. Schema is the technical term used by cognitive scientists to describe how people process, organize, and store information in their heads. Schemas, or schemata, are seen as cognitive constructs by which we organize information in our long-term memory (Widdowson, 1983). They "reflect the experiences, conceptual understanding, attitudes, values, skills, and strategies ...[we] bring to a text situation" (Vacca \& Vacca, 1999, p. 15). Schemata, therefore, have been called "the building blocks of cognition" (Rumelhart, 1982) because they represent elaborate networks of information that people use to make sense of new stimuli, events, and situations.

Schema theory is based on the belief that "every act of comprehension involves one's knowledge of the world" (Anderson et al. 1977, cited in Carrell \& Eisterhold, 1983, p. 73). Similarly, and more elaborately, Smith, (1994, p. 8) states:

Everything we know and believe is organized in a theory of what the world is like, a theory that is the basis of all our perceptions and understanding of the world, the root of all learning, the source of hopes and fears, motive and expectancies, reasoning and creativity. And this theory is all we have. If we make sense of the world at all, it is by interpreting our interactions with the world in the light of our theory. The theory is our shield against bewilderment.

\section{SCHEMA THEORY AND READING COMPREHENSION}

Research on the theory of schema had great impact on understanding reading comprehension in first and second language. It made clear the case that understanding the role of schema in the reading process provides insights into why students may fail to comprehend text material. Most, if not all, research in this area seem to agree that when students are familiar with the topic of the text they are reading (i.e., possess content schema), aware of the discourse level and structural make-up of the genre of the text (i.e., possess formal schema), and skillful in the decoding features needed to recognize words and recognize how they fit together in a sentence (i.e., possess language schema), they are in a better position to comprehend their assigned reading. Deficiency in any of the above schemas will result in a reading comprehension deficit. As Carrell (1988b) points out, "students' apparent reading problems may be problems 
of insufficient background knowledge [content, formal, and linguistic]" (p. 245). However, as further pointed out by the same author, students might have sufficient schemata, yet unable to comprehend the text if such schemata are not appropriately activated.

According to Brown (2001) the hallmark of schema theory, with regards to reading, is that a text does not by itself carry meaning. The reader brings information, knowledge, emotion, and culture - that is schemata, to the printed word. Clark and Silberstein (1977, quoted in Brown 2001) indicate that research has shown that reading is only incidentally visual. More information is contributed by the reader than by the print on the page. This would all seem to point to the fact that our understanding of a text depends on how much related schema we, as readers, possess while reading. Consequently, readers', natives and non-natives, failure or confusion to make sense of a text is caused by their lack of appropriate schemata that can easily fit with the content of the text. This lack of appropriate schemata can be either formal or content-based. Brown (2001) defines these two as follows: content schemata includes what we know about people, the world, culture, and the universe, while formal schemata consists of our knowledge about discourse structure.

Perhaps one of the most important schemas that pose immediate threat to students is content, or topical schema. As Aebersold \& Field (1997) assert "If the topic ....is outside [students'] experience or base of knowledge, they are adrift to an unknown sea" (p. 41). Ways of activating content schema, I believe, is an area that needs further exploration.

\section{CONTENT SCHEMA}

As mentioned earlier, research in the area of schema theory and reading comprehension concluded that the closer the match between the reader's schema and the text, the more comprehension occurs. Comprehension of any kinds depends on knowledge; that is, relating what we don't know (i.e., new information, to what we already know, which is not a random collection of facts but a theory of the world. In other words, our understanding of a text depends on how much related schema we, as readers possess while reading. Consequently, failure of L1 or L2 readers to make sense of a text is caused by their lack of an appropriate schema that can easily fit within the content of the text. This missing of an appropriate schema can be content, formal or linguisitc. Since I am more concerned with the content-based aspect of schema, I will limit my discussion to some of the most important studies in this regard as they relate to both L1 and L2 readers. Then, I will concentrate my discussion on the reading comprehension of the ESL reader.

Content schema refers to the familiarity of the subject matter of the text. It includes an understanding of the topic of the text and the cultural-specific elements needed to interpret it. Content schema is part of the individual's cultural orientation, and since culture affects all aspects of life, it certainly has a major impact on all elements of reading. Some of these elements include things such as what types of text people read? What is the purpose of reading? How reading is perceived? How readers of a text view themselves in relation to the writer of the text? Superior? Inferior? Active participants? Passive participant? What is the level of textual engagement people expect? What is the value of the spoken word in relation to the written word? And what topics are worthy of reading? Answers to all these questions are usually culturally determined, learned, understood, and put into practice. Although idiosyncrasy cannot be ignored, one's cultural orientation appears to be a dominant force in shaping one's reading habits. Therefore, a reader is most likely to fail if his/her cultural schema is different from the one proposed by the text. As pointed out by Carrell \& Eisterhold (1983, p. 80) "one of the most obvious reasons why a particular content schema may fail to exist for a reader is that the schema is culturally specific and is not part of a particular reader's cultural background." Some research in support of the role of content schema in L1 and L2 reading comprehension is reviewed below.

Steffensen, Joag-Dev and Anderson (1979, cited in Bernhardt, 1991) presented separate letters about American and Indian weddings to university students whose native culture was either American or Indian. Wedding customs differ in America and India and subjects tend to recall information that was relevant to their culture. In addition, when recalling information about a culturally unfamiliar text, subjects tend to distort information and insert ideas from their own culture to overcompensate for absent schemata. Subjects were also found to elaborate the 
passages related to their own cultural experiences, and to read them faster. Kathryn $\mathrm{Hu}-\mathrm{Pei} \mathrm{Au}$, is an educational psychologist chiefly concerned with schema theory as it applies to native speaking minority children. In a 1979 study, she emphasized the importance of children's experiences. According to Au, the child's experiences contribute to reading achievement when the school uses a basal text containing stories directly related to the child's own world. Koh (1986) also related understanding to the reader's prior knowledge and found that a combination of linguistic proficiency and prior knowledge is important for comprehension. The lack of either one, according to Koh, is sometimes compensated for by the presence of the other.

According to Carrell (1981) the text must activate, in the reader, all of the appropriate cognitive schemata in order to be comprehended. When reading a story with a familiar theme, especially one from the native culture, L2 readers might more easily activate the appropriate background concepts and hence more efficiently process the text. Not only is it important for the reader to have the background knowledge to read more efficiently, but that knowledge also needs to be activated. This can be done through pre-reading activities, as indicated by Koh (1986) and Williams (1987).

Furthermore, Winfield and Barnes-Felfeli (1982) observed a class of twenty intermediate level ESL students, half of whom were Hispanic, the other half was comprised of Hebrew, Arabic, Navajo, Greek, and other non-native speakers of English. The class was asked to read a sixth grade level passage of two translated texts: Don Quixote and one on the Japanese Noh theater. The subjects were to read the passages and then were allowed 15 minutes to write about everything they could recall from the text. All of the students in this study had pre-reading activities but different levels of background knowledge about the topics. While the non-Hispanic students performed consistently on both texts, the Hispanic students exhibited a much greater range. They scored below the others on the Noh text but much higher on Don Quixote. The reason, according to the researchers, is that familiar material increases fluency.

Kaplan (1966), Long (1989), and Nostrand (1989) also indicate that culturally specific schemata affects comprehension. Nostrand, for example, has shown that authentic texts from one culture may give a false impression of that culture to members of a second culture. To avoid this false impression, such texts should be presented in authentic context and students' appropriate schema should be activated. According to Kaplan, cultural differences lead to different approaches to teaching reading to L1 speakers and L2 speakers. Cultural knowledge is also important because to comprehend some types of writing, humor, for example, a knowledge of the culture must be taken into consideration. Garfield, a US cartoon, translated into a second language, is humorous only in those situations in which the reader understands the cultural significance behind it.

This is true of other genres as well. Carrell's (1981) study, has shown the effects on comprehension and recall of English stories by ESL readers based on cultural origin of the stories given for them. She gave two groups of students; Chinese and Japanese, stories in English which had been translated from Chinese, Japanese, French, and American Indian folktales. The results showed that where story schemata differed drastically from that of their own culture, students ranked comprehensibility of the passages concerned as low. Their rewriting of those stories was also ranked low in comprehensibility by American native speakers. Johnson (1981) found similar effects of the unfamiliar cultural background of a text on reading comprehension. By examining the language complexity and the cultural origin of prose on the reading comprehension of Iranian students (intermediate and advanced ESL students), she found that the level of syntactic and semantic complexity of the stories had a lesser effect on reading comprehension than did the cultural origin (Iranian versus American folktales) of the story.

A study conducted by Koh (1986) to show the effects of familiar context on student's reading comprehension supports the notion that one's comprehension of a text depends on how much relevant prior knowledge the reader has about the subject matter of that particular text. He went further to suggest that students must be made conscious of what is involved in successful reading. In other words, they must activate their content schemata for the recreating of meaning from the text rather than focus on the word-for-word deciphering which characterizes much ESL reading material. 


\section{L2 READERS AND THE ACTIVATION OF CONTENT SCHEMA}

As pointed out by Carrell (1983), among others, cultural specificity of texts indicated that teachers must be sensitive to potential comprehension difficulties which ESL/EFL readers may encounter with a text due to a lack of familiarity with the culture-specific content the text presumes. Therefore, teaching L2 students to read is not achievable by simply choosing any text or reading materials and expecting the students to make sense out of them. ESL reading teachers should realize that the extent to which L2 readers are familiar with the content of the text has a large impact on their reading comprehension. Carrell $(1983,1987)$ indicates that ESL/EFL teachers should also work on minimizing their students' reading difficulties by providing them with familiar contents that include relevant cultural information. The selected reading materials must activate students' relevant schemata which will then lead to a better understanding of what is being read. Carrell (1983), Williams (1987), and other researchers showed that ESL reading comprehension may be affected not because the ESL readers lack the appropriate schema, but because they fail to activate it.

For the teacher, then, the importance of background knowledge has three main implications: first, the teacher must take into account the knowledge on which any written text is based. Second, if a reader is not actively using his/her background knowledge, a significant part of the reading process is not taking place. Third, teachers should have as their principal objective the development of problem-solving, creative, interpretive strategies in which the students can exploit whatever knowledge or resources they may have. Teachers, therefore, in teaching students to activate and use their background knowledge, are helping them to become better readers.

All of this leads us to the importance of how to take content schema into consideration in our teaching. Williams (1987) gives three phases - which he calls the pre-reading phase, the reading phase, and the post-reading phase - - for teaching reading comprehension. Of these, the most important for building background knowledge is the first, pre-reading phase wherein the instructor has the opportunity to use pictures, slides, movies, games and other such devices to activate and build upon the students' schema. In this phase, students might also be asked to write about their knowledge of the subject and, after writing, discuss their knowledge with other students. In the second phase, reading, the students read about the subject. In this way they continue to build upon their own existing schema. Each time they read on the same subject, their knowledge of the subject becomes greater. Then, through the activities of the third, post-reading phase, they students integrate this background into a new schema structure.

Take, as an example of how this works, that your students have been assigned to read a selection about an American folk hero such as Johnny Appleseed. You might start your class with students writing about a folk hero or holiday in their own culture. To do this, just give them ten to fifteen minutes to write anything they can think of about the folk hero/holiday they selected. At this stage, if the students don't know a word, have them put it in their own language, leave a space, or put in a scribble. By writing in this way, students start thinking about the topic and start activating their background knowledge about folk holidays in general. After students have finished writing, put them into small groups to discuss what they have written. This will help them hear what others have said about folk heroes/holidays, enabling them to recall more. After ten or fifteen minutes talking about the topic in small groups, you can have the whole class take part in a general discussion of the topic. The reason for having small group discussions is that many students talk more freely in small groups than in large classes. Further, if the class is too large, there won't be enough time for everyone to participate. Of course, you know your own students better than anyone else does, so if you feel it necessary to skip a step, do so. You might want to go straight from writing to class discussion, or skip writing and go to small group discussion, or even start off with a general class discussion of folk holidays. The important point is to have the students recognize, when you mention "Johnny Appleseed Day," that they have related schemata in their own culture.

After the students recognize that there are folk heroes/holidays in different cultures, you can start asking the class to talk about different types of folk heroes. Since the importance of Johnny Appleseed Day is that this man supposedly traveled from Pennsylvania to Ohio in the late 1700s planting apple seeds and never accepting money; this could lead to discussions about other national figures in the US or other countries who were/are philanthropists. Each of these activities builds on the students' existing schemata, first by activating it, then by adding new information that can be integrated into what becomes a new and greater schema. 
Having used the pre-reading phase to activate and enlarge their background knowledge, the students are then introduced to the reading selection. After having the students skim the selection, you can have them read it in depth, making notes of the new information they find. Then through a series of comprehension questions, vocabulary games, and acting out the selection, the students begin to integrate this new knowledge into a greater schema.

Krashen (1993) suggests two ways to activate the students' schemata. The first, Free Voluntary Reading, is to have the students select and read texts that are of interest to them, with no need to worry about accountability. In other words, reading itself will help build the familiarity necessary to read more advanced books. His second suggestion is to have them read in their first language so as to build up the knowledge base necessary to understand the material in the second language. A student, for example, who has no familiarity with the subject of computers will have trouble understanding a book about computers in the target language (and may, through lack of familiarity with the subject matter, even have trouble understanding it in his/her first language). If, on the other hand, this same student has read a lot about computers in his/her first language, then, since the material would be familiar, the selection in the target language would be easier to understand.

Extensive reading has also been advocated by many researchers (see esp. Wallace, 1992; McCarthy \& Carter, 1994, Bamford \& Day, 1997, Day \& Bamford, 1998; 2002); however, despite its inherent positive effects some authors have voiced concerns about the feasibility of incorporating it into the curriculum. Grabe (2002), for example, discusses some of the dilemmas associated with extensive reading including the need to educate administrators and teachers about the importance of extensive pleasure reading, and supplying classrooms and libraries with reading resources that can excite students to read. In addition, specific times in the school curriculum should be devoted to pleasure reading on a regular basis and time must be devoted to developing students' motivation and to turning them into independent readers (Grabe, p. 281).

\section{IMPLICATIONS AND CONCLUDING REMARKS}

As discussed earlier, few studies have been conducted to show the importance of prior knowledge of the world on ESL/EFL learners' reading comprehension. All of these studies emphasized the fact that the ability to understand a text is based not only on the reader's linguistic knowledge, but also on general knowledge of the world and the extent to which that knowledge is activated during processing. The results of all these studies and the view of reading comprehension as an interactive process between the reader and the text (Rosenblatt, 1994) lead to several implications for the ESL teacher. If the unfamiliar content of a text, whether cultural or topic-related, has an effect on reading comprehension, then this fact must be considered as a criterion in the selection of reading materials and also in the evaluation of reading comprehension. Therefore knowledge of schema theory is of particular importance to teachers who are responsible for recommending materials for reading instruction. According to schema theory, our background knowledge (schemata) and its relevancy to the text that is being read, determines the ease or complexity of understanding that particular text. In other words, no matter how well a reader may know a language, he or she cannot read in that language with good comprehension if the subject matter or the content of the text is one he or she knows absolutely nothing about. To understand a line such as 'The runner was called out at the plate,' the reader must have acquired a kind of "baseball schemata," i.e., an organized understanding or model of the game within which words like "runner," "plate," and "out" have special meaning and relate to each other in special ways (Carrell \& Eisterhold, 1983). The understanding of this line by an ESL student who does not have a clue about what a baseball game is depends mainly on his or her ESL teacher's ability to activate the student's related schemata through classroom activities and teaching techniques.

Finally, I suggest that teachers should ask themselves the following questions before deciding on which reading materials are to use in $\mathrm{L} 2$ classrooms.

1. Will my students be interested in reading such materials?

2. Will these materials be relevant to my students' English proficiency levels?

3. What content knowledge is to be extracted from these materials?

4. Will these materials cause cultural conflicts in the classroom?

5. How can I motivate my students and involve them in reading such materials? 
6. What kinds of pre-reading, reading, and post-reading activities and materials can be designed to increase my students' understanding of these materials?

7. Do the reading materials provide students with sufficient background information about the content of the text?

8. How much time and freedom am I giving my students to exercise their understandings of the materials?

9. Am I being sensitive to my students' hidden comprehension problems?

10. Am I helping my students become more aware of the fact that reading is a highly interactive process?

11. Are my students changing their attitudes about reading?

12. Am I allowing my students to become independent, self-directed readers?

If we, as teachers, ask ourselves these questions before selecting a reading text, while the students are reading it, and after they have finished it, then we can fairly certain that our students will become more secure and more independent readers in their second language.

\section{REFERENCES}

1. Aebersold, J. A., \& Field, M. L. (1997). From reader to reading teacher. Cambridge: Cambridge University Press.

2. Au, K.H. (1979). Using the experience-text-relationship method with minority children. The Reading Teacher, 32, 677-679.

3. Bamford, J. \& Day, R. R. (1997). Extensive reading: What is it? Why bother? The Language Teacher, 21(5), 6-8, 12.

4. Bernhardt, E.B. (1991). Reading development in a second language: Theoretical, empirical and classroom perspectives. Norwood, NJ: Ablex Publishing Corporation.

5. Brown, H.D. (2001). Teaching by principles: An interactive approach to language pedagogy. White Plains, NY: Addison Wesley Longman, Inc.

6. Carrell, P. L. (1981). Culture-specific schemata in L2 comprehension. In R. Orem \& J. Haskell (Eds.), Selected papers from the Ninth Illinois TESOL/BE Annual Convention, First Midwest TESOL Conference (pp. 123-132). Chicago: Illinois.

7. Carrell, P.L. (1982). Three components of background knowledge in reading comprehension. Language Learning, 33, 183-201.

8. Carrell, P.L. (1983). Some issues in studying the role of schemata or background knowledge in second language comprehension. Reading in a Foreign Language, 1, 81-92.

9. $\quad$ Carrell, P.L. (1987). Readability in ESL. Reading in a Foreign Language, 4, 21-41.

10. Carrell, P.L. (1988b). Interactive text processing; Implications for ESL/second language reading. In P, L. Carrell, J. Devine \& D.E. Eskey (Eds.) (1988) Interactive Approaches to second language reading. Cambridge: Cambridge University Press.

11. Carrell, P.L. \& Eisterhold, J.C. (1983). Schema theory and ESL reading pedagogy. TESOL Quarterly, 17, 553-569.

12. Day, R. R. \& Bamford, J. (1998). Extensive reading in the second language classroom. Cambridge: Cambridge University Press.

13. Day, R. R. \& Bamford, J. (2002). Top ten principles for teaching extensive reading. Reading in a Foreign Language, 14 (2)

14. Grabe, W. (2002). Dilemmas for the development of second language reading abilities. In J.C.Richards and W.A. Renandya (Eds.), Methodology in Language Teaching (pp. 276-286). Cambridge: Cambridge University Press.

15. Johnson, P. (1981). Effects on reading comprehension of language complexity and cultural background of a text. TESOL Quarterly, 15 (2), 169-181.

16. Kaplan, R.B. (1966). Cultural thought patterns in intercultural education. Language Learning, 16, 1-20.

17. Koh, M.Y. (1986). The role of prior knowledge in reading comprehension. Reading in a Foreign Language, 3, 375-380.

18. Krashen, S. (1993). The power of reading: Insights from the research. Englewood, CO: Libraries Unlimited, Inc. 
19. Long, D. R. (1989). Second language listening comprehension: A schema-theoretic perspective. The Modern Language Journal, 73, 32-40.

20. McCarthy, M. \& Carter, R. (1994). Language and discourse: Perspective for language teaching. London: Routledge.

21. Nostrand, H.L. (1989). Authentic texts and cultural authenticity: An editorial. The Modern Language Journal, 73, 49-52.

22. Rosenblatt, L.M. (1994). The reader, the text, the poem. Carbondale, IL: Southern Illinois University Press.

23. Rumelhart, D. E. (1982). Schemata: The building blocks of cognition. In J. Guthrie (Ed.), Comprehension and teaching: Research reviews (pp. 3-26). Newark, DE: International Reading Association.

24. Smith. F. (1994). Understanding reading (5 $5^{\text {th }}$ ed.). Hillsdale, NJ: Lawrence Erlbaum Associates, Publishers.

25. Wallace, C. (1992). Reading. Oxford: Oxford University Press.

26. Williams, E. (1987). Classroom reading through activating content-based schemata. Reading in a Foreign Language, 4, 1-7.

27. Winfield, F.E. \& Barnes-Felfeli, P. (1982). The effects of familiar and unfamiliar cultural context on foreign language composition. Modern Language Journal, 66, 373-378.

28. Widdowson, H. G. (1983). Learning purpose and language use. Oxford: Oxford University Press.

29. Vocca, R. T. \& Vocca, J. L. (1999). Content area reading: Literacy and learning across the curriculum $\left(6^{\text {th }}\right.$ Ed.). New York: Longman. 


\section{$\underline{\text { Notes }}$}

